\title{
Size, position, and timing: A mixture of success
}

\author{
Antonio Miceli, MD, PhD, Antonio Lio, MD, and Mattia Glauber, MD
}

\author{
From the Istituto Clinico Sant'Ambrogio Dipartimento Cardiotoracico Gruppo Ospedaliero San Donato, Milan, \\ Italy. \\ Disclosures: Authors have nothing to disclose with regard to commercial support. \\ Received for publication March 10, 2016; accepted for publication March 14, 2016; available ahead of print April \\ 23, 2016. \\ Address for reprints: Antonio Miceli, MD, PhD, Istituto Clinico Sant'Ambrogio Dipartimento Cardiotoracico \\ Gruppo Ospedaliero San Donato, Via Faravelli 16, 20149 Milan, Italy (E-mail: antoniomiceli79@alice.it). \\ J Thorac Cardiovasc Surg 2016;152:633-4 \\ $0022-5223 / \$ 36.00$ \\ Copyright (C) 2016 by The American Association for Thoracic Surgery \\ http://dx.doi.org/10.1016/j.jtcvs.2016.03.034
}

The incidence of pacemaker (PM) implantation after aortic valve replacement with a sutured prosthetic valve ranges between $6 \%$ and $10 \% .^{1,2}$ The most common contributing factor for PM implantation is mechanical trauma to the conduction system, which is often due to extensive debridement of a calcified aortic annulus or to the insertion of deep stitches that cause a direct injury to the atrioventricular bundle. A surgeon may take steps to pay more attention to these causes, but other potential risk factors may increase the risk for PM implantation. Specifically, a disturbance of the preoperative cardiac rhythm, such as right bundle branch block, bifascicular block, left bundle block, and atrial fibrillation, may be associated with a high incidence of permanent postoperatory atrioventricular block. ${ }^{3}$ In addition, older age, poor left ventricular ejection fraction, left ventricular septum hypertrophy, redo surgery, valve size, prolonged operative times, and postoperative events such as electrolyte imbalance myocardial infarction or systemic hypoperfusion may contribute to conduction failure. ${ }^{4,5}$ In other words, the risk of PM implantation is multifactorial and cannot be related only to the type of valve implanted. Nevertheless, in recent years, there has been increasing evidence that sutureless aortic valves are associated with higher incidence of PM implantation compared with conventional surgical aortic valve replacement. ${ }^{6}$

Yanagawa and colleagues ${ }^{7}$ describe a simple technical modification of Perceval (Livanova, Italy) device insertion resulting in lower rate of conduction disturbance rhythm necessitating temporary and permanent PM implantation. Specifically, rate of PM implantation went from $28 \%$ to $0 \%$ after the technical modification.

The users' instructions for the Perceval device recommend placing the guiding sutures $3 \mathrm{~mm}$ below the nadir of the annulus. However, after a careful echocardiographic evaluation of these patients, some authors ${ }^{8}$ have realized that the lower the position of the valve in respect to the aortic annulus, the higher the chance of PM insertion. We are the first group reporting a low rate of PM implantation

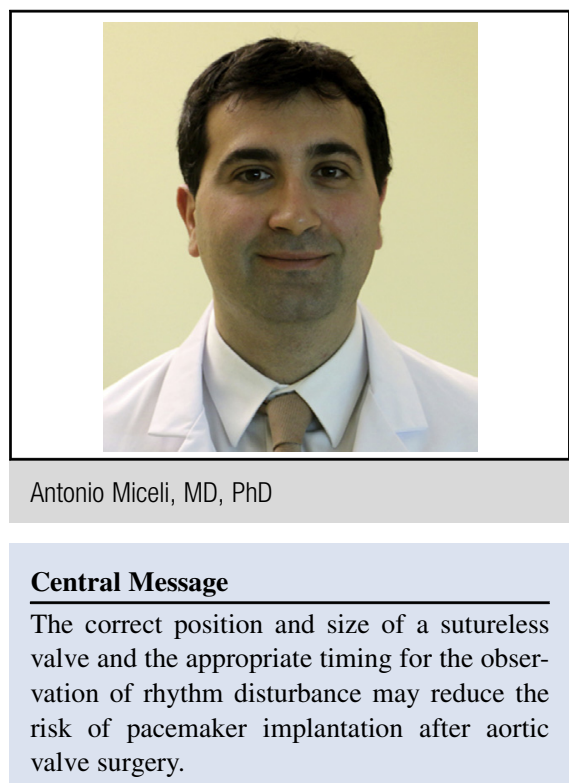

See Article page 630.

$(4.8 \%)^{8}$ and now at Istituto Clinico Sant'Ambrogio (data not published), our rate is identical to that found by Yanagawa and colleagues, ${ }^{7}$ who report $0 \%$ PM implantation in almost 80 patients undergoing aortic valve replacement. To have a perfect sealing of this valve into the aortic annulus is necessary so that the prosthetic annular gown covers thoroughly the native aortic annulus. If the Perceval is positioned some millimeters lower, the self-expanded nitinol stent may compress the conduction bundles and cause atrioventricular block. In addition, this might reduce the rate of paravalvular leakage. Sizing is another crucial aspect to avoid PM insertion. The authors ${ }^{7}$ show in their report that patients receiving extra-large valves had higher rates of temporary and permanent pacing. This presupposes that in case of incorrect sizing, the risk of PM may be higher if a larger valve is chosen. Mazine and colleagues $^{9}$ reported an incremental increase of PM implantation with increasing prosthesis size.

Finally, the propensity of the local electrophysiology cardiologists may affect the rate of PM implantation in the presence of cardiac rhythm disturbances. ${ }^{10}$ According to American College of Cardiology/American Heart Association guidelines, ${ }^{11}$ the decision to implant a PM, as well as timing, is left to the treating physician's discretion. Nevertheless, the most recent European guidelines ${ }^{12}$ recommend a period of clinical observation up to 7 days to assess whether the rhythm disturbance is transient and resolves. 
Previously we have described some rules for a successful implantation of a Perceval valve, ${ }^{13}$ and this article ${ }^{7}$ adds evidence that if the valve is correctly sized and well positioned, complications may not occur. However, the sample size is relatively low and some rhythm conduction disturbances after surgical procedure might happen in the future. Finally, there is another aspect that is yet to be addressed but that we think it might lower the risk of PM implantation. Livanova, the manufacturer of the Perceval device, recommends ballooning the implanted valve for 30 seconds at a pressure of $4 \mathrm{mBar}$. We strongly believe that this additional procedure might create an injury of the conduction system. The simple use of warm saline solution is all that is necessary to set the new prosthesis in its position.

\section{CONCLUSIONS}

Pacemaker implantation is multifactorial and Yanagawa and colleagues ${ }^{7}$ have shown that in the absence of other potential risk factors, the use of sutureless valves may not be associated with conduction disturbance. The identification of preoperative rhythm disturbance, the correct sizing of valves, and a proper implantation may help surgeons avoid this postoperative complication.

\section{References}

1. Dawkins S, Hobson AR, Kalra PR, Tang AT, Monro JL, Dawkins KD. Permanent pacemaker implantation after isolated aortic valve replacement: incidence, indications, and predictors. Ann Thorac Surg. 2008;85:108-12.

2. Schurra UP, Berlia J, Berdajsb D, Häuslera A, Dzemalia O, Emmertc M, et al. Incidence and risk factors for pacemaker implantation following aortic valve replacement. Interact Cardiovasc Thorac Surg. 2010;11:556-60.

3. Koplan BA, Stevenson WG, Epstein LM, Aranki SF, Maisel WH. Development and validation of a simple risk score to predict the need for pacemaker implantation after cardiac valve surgery. J Am Coll Cardiol. 2003;41:795-801.
4. Silvero M, Browne L, Solari G. Pacemaker following adult cardiac surgery. In: Min M, ed. Cardiac Pacemakers - Biological Aspects, Clinical Applications and Possible Complications. In Tech; 2011:135-60. Available at: http://www. intechopen.com/books/cardiac-pacemakers-biological-aspects-clinical-applica tions-and-possible-complications/pacemaker-following-adult-cardiac-surgery 1. Accessed April 13, 2016.

5. Erdogan HB, Kayalar N, Ardal H, Omeroglu SN, Kirali K, Guler M, et al. Risk factors for requirement of permanent pacemaker implantation after aortic valve replacement. J Card Surg. 2006;21:211-5.

6. D'Onofrio A, Rizzoli G, Messina A, Alfieri O, Lorusso R, Salizzoni S, et al. Conventional surgery, sutureless valves, and transapical aortic valve replacement: what is the best option for patients with aortic valve stenosis? A multicenter, propensity-matched analysis. J Thorac Cardiovasc Surg. 2013;146: 1065-70.

7. Yanagawa B, Cruz J, Boisvert L, Bonneau D. A simple modification to lower incidence of heart block with sutureless valve implantation. J Thoracic Cardiovascular Surg. 2016:152:630-2.

8. Miceli A, Santarpino G, Pfeiffer S, Murzi M, Gilmanov D, Concistrè G, et al. Minimally invasive aortic valve replacement with Perceval S sutureless valve: early outcomes and one year survival from two European centers. J Thoracic Cardiovasc Surg. 2014;148:2838-43.

9. Mazine A, Teoh K, Bouhout G, Bhatnagar G, Pelletier M, Voisine P, et al. Sutureless aortic valve replacement: a Canadian multicenter study. Can J Cardiol. 2015;31:63-8.

10. Nguyen A, Fortin W, Mazine A, Bouchard D, Carrier M, El Hamamsy IE, et al. Sutureless aortic valve replacement in patients who have bicuspid aortic valve. J Thoracic Cardiovasc Surg. 2015;150:851-7.

11. Epstein AE, DiMarco JP, Ellenbogen KA, Estes NA III, Freedman RA, Gettes LS, et al. ACC/AHA/HRS 2008 guidelines for device-based therapy of cardiac rhythm abnormalities: a report of the American College of Cardiology/ American Heart Association Task Force on Practice Guidelines (Writing Committee to Revise the ACC/AHA/NASPE 2002 Guideline Update for Implantation of Cardiac Pacemakers and Antiarrhythmia Devices). Circulation. 2008;117: e350-408.

12. Brignole M, Auricchio A, Baron-Esquivias G, Bordachar P, Boriani G, A-Breithardt O, et al. 2013 ESC guidelines on cardiac pacing and cardiac resynchronization therapy. The task force on cardiac pacing and resynchronization therapy of the European Society of Cardiology (ESC). Developed in collaboration with the European Heart Rhythm Association (EHRA). Eur Heat J. 2013;34:2281-329.

13. Glauber M, Ferrarini M, Lio A, Miceli A. Dealing with a stenotic bicuspid valve: is this still an off-label procedure for a sutureless valve? J Thoracic Cardiovasc Surg. 2015;150:858-9. 